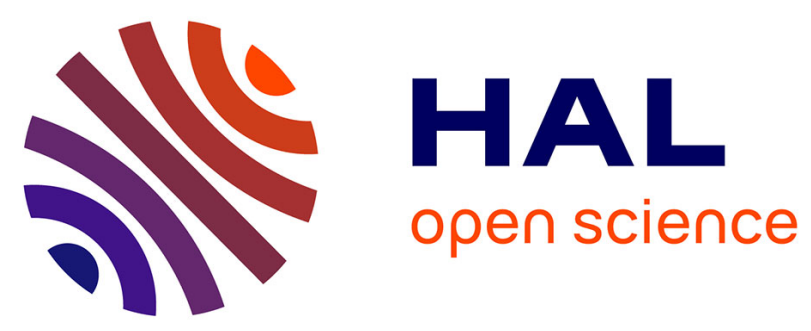

\title{
From Web Analytics to Product Analytics: The Internet of Things as a New Data Source for Enterprise Information Systems
}

\author{
Wilhelm Klat, Christian Stummer, Reinhold Decker
}

\section{To cite this version:}

Wilhelm Klat, Christian Stummer, Reinhold Decker. From Web Analytics to Product Analytics: The Internet of Things as a New Data Source for Enterprise Information Systems. 10th International Conference on Research and Practical Issues of Enterprise Information Systems (CONFENIS), Dec 2016, Vienna, Austria. pp.145-155, 10.1007/978-3-319-49944-4_11 . hal-01630526

\section{HAL Id: hal-01630526 \\ https://hal.inria.fr/hal-01630526}

Submitted on 7 Nov 2017

HAL is a multi-disciplinary open access archive for the deposit and dissemination of scientific research documents, whether they are published or not. The documents may come from teaching and research institutions in France or abroad, or from public or private research centers.
L'archive ouverte pluridisciplinaire HAL, est destinée au dépôt et à la diffusion de documents scientifiques de niveau recherche, publiés ou non, émanant des établissements d'enseignement et de recherche français ou étrangers, des laboratoires publics ou privés. 


\title{
From Web Analytics to Product Analytics: The Internet of Things as a New Data Source for Enterprise Information Systems
}

\author{
Wilhelm Klat, Christian Stummer, and Reinhold Decker \\ Faculty of Business Administration and Economics, Bielefeld University, \\ Universitaetsstr. 25, 33615 Bielefeld, Germany, \\ \{wilhelm.klat, christian.stummer,rdecker\}@uni-bielefeld.de
}

\begin{abstract}
The internet of things (IoT) paves the way for a new generation of consumer products that collect and exchange data, constituting a new data source for enterprise information systems (EIS). These IoTready products use built-in sensors and wireless communication technologies to capture and share data about product usage and the environment in which the products are used. The dissemination of the internet into the physical world of everyday products thus establishes new opportunities to apply methods well-established in web analytics to IoT-products, allowing enterprises to tap into a new and rich source of consumer data. In this paper we examine technical challenges of enabling everyday products to generate consumer data for EIS and discuss the application of web analytics methods to IoT-ready consumer products.
\end{abstract}

Keywords: Internet of things, Product analytics, Enterprise information systems

\section{Introduction}

A growing number of recently introduced new consumer products are able to sense their environment and share data with users, other products, and companies via the internet of things (IoT). Examples are $L G$ 's refrigerator "Smart ThingQ", $V W$ 's smart minivan "BUDD-e", Sleep Number's mattress "It Bed", or Verbund's energy monitoring and controlling system "Eco-Home". These products have in common that they extend the basic functionalities of regular products with the ability to collect and share data $[2,22,27,28]$. We call this new category of data-collecting and -sharing products IoT-ready products (or for short, IoT-products). The IoT was not established at a specific point in time; rather, it has emerged in a continuous, and still ongoing, process. It can be interpreted as "a global network infrastructure, linking physical and virtual objects through the exploitation of data capture and communication capabilities" [5]. Accordingly, for the purpose of this paper we define an IoT-product as a consumer product that autonomously collects and exchanges consumer data.

The IoT is a potential game changer for nearly every business and it has received attention by both academia and practitioners around the world (for a 
recent overview of research trends and challenges see $[52,53])$. From the perspective of enterprise information systems (EIS), the IoT will be the key to unlocking the full potential of EIS (see, for example, [40]). Conceptual designs for corresponding EIS have already been outlined in prior work (e.g., [26, 50]). Our approach differs from these approaches by focusing on consumer data that is collected by the physical IoT-products themselves in the consumer's environment. While websites, social networks, search engines, and other traditional sources for data generation in sales market research are built on the traditional internet and the World Wide Web, IoT-products provide enterprises with access to a new kind of data. With traditional products, enterprises lose direct access to their products at the point of sale [27]. With IoT-products, however, enterprises have the opportunity to gain insights into the actual interaction of customers with their products as well as collecting additional data from the customer's environment, which provides these enterprises with access to large amounts of longitudinal data in a way that has not been previously available [37]. The data collected by IoT-products primarily supports decision making in marketing and sales, but other enterprise divisions and EIS-subsystems may also benefit from this data (see Fig. 1). The car manufacturer Tesla, for instance, has already captured data about 780 million miles of driving from its IoT-ready cars, using the data to improve the technical functionality of the autopilot and to optimize the user interface [8].

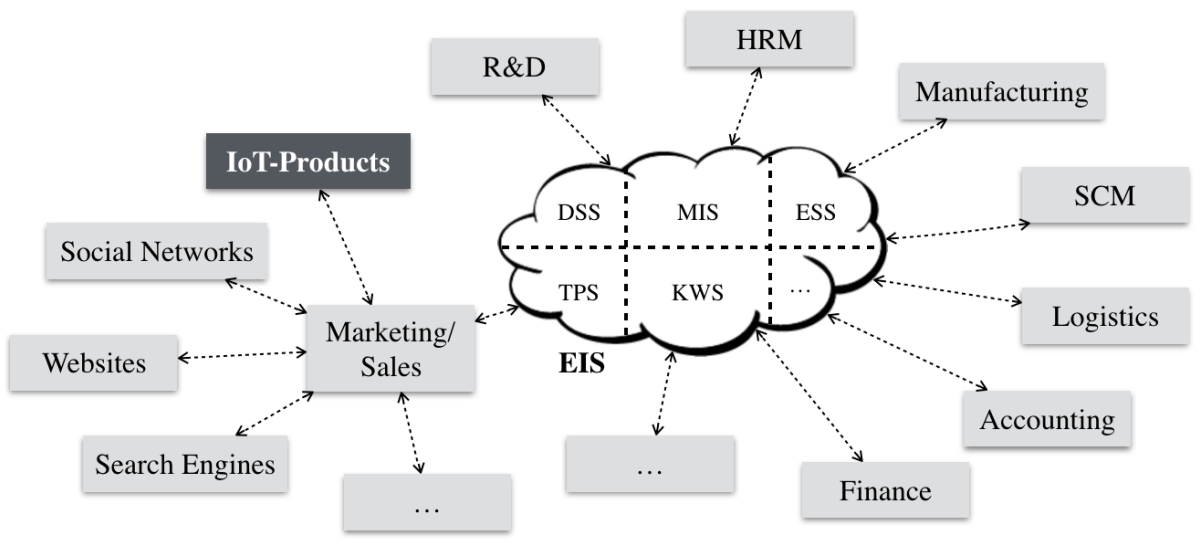

Fig. 1. IoT-products as a new data source for Enterprise Information Systems (see, for example, [32]). DSS = Decision Support Systems, MIS = Management Information System, ESS = Executive Support Systems, TPS = Transaction Processing Systems, KWS $=$ Knowledge Work Systems

The new opportunities for data collection and analysis from connected everyday products emerge from a concept we refer to as "product analytics" (see also [20]). Product analytics is the IoT-equivalent of web analytics and aims at 
the autonomous collection and analysis of usage data from the customers' environment. IoT-products thus constitute a promising platform for the application of analytics technologies that have already proven their effectiveness on the web and on mobile phones. The research contribution of this paper therefore lies in the exploration and discussion of the new data collection opportunities embodied by IoT-products for enterprise information systems.

Accordingly, the remainder of the paper is organized as follows: Section 2 deals with technical aspects of IoT-products and outlines major challenges of transforming traditional products into IoT-ready ones with respect to technologies for data collection, data exchange, and energy supply. Section 3 then focuses on the vital aspect of data collection and discusses the application of established methods from web analytics to IoT-products. The paper concludes with a summary and suggestions for promising research directions in Section 4.

\section{Technical Foundation of IoT-Products}

The application of product analytics to physical consumer products requires them to be ready for the IoT. The core components for this purpose are (i) sensors and processors for data collection and processing, (ii) transceivers for wireless data exchange, and (iii) energy supply (see Fig. 2).

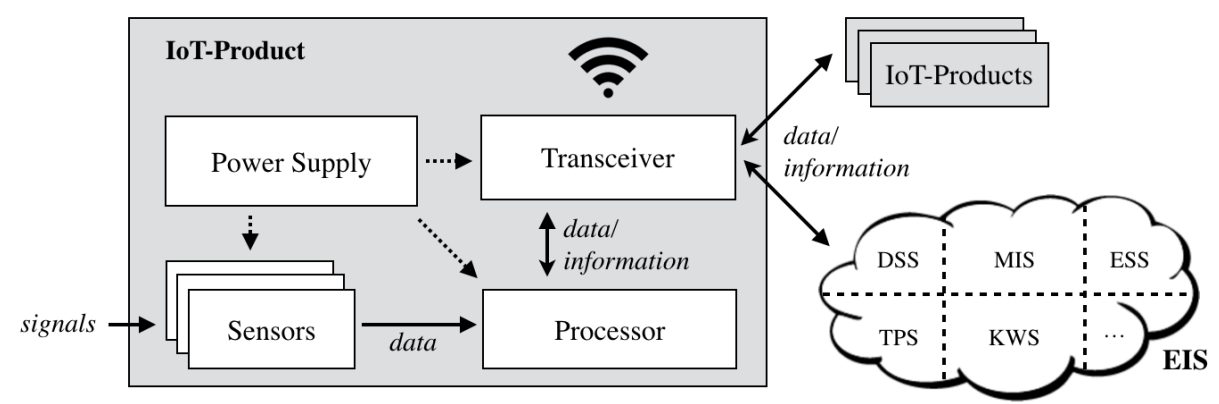

Fig. 2. Components of IoT-products necessary for product analytics

Integrating these IoT-components seems rather trivial for large-sized products that provide sufficient space, can draw on a genuine energy supply, and already have built-in sensors or communication technologies (e.g., in-home health care devices, as described in [33]). Readying everyday products such as shoes, watches, or flower pots for the IoT, though, still constitutes a technical challenge. However, such small everyday IoT-products in particular exhibit a huge potential for generating rich consumer data [1]. Tracking a consumer's number of daily footsteps may serve as an illustrative example. A smartphone infers this data by tracking movement with GPS, accelerometers, and other built-in sensors. IoT-ready shoes, in contrast, are much closer to the event of interest and 
therefore can capture footsteps directly and more precisely including the actual number of steps, the pressure applied, the weight distribution between the feet, and much more. The rich data from IoT-ready shoes therefore offer enterprises from industries such as footwear manufacturing to healthcare a highly valuable opportunity to better understand individual usage patterns and to offer databased services. The IoT-pioneer Orpyx, which offers IoT-ready shoe inserts that transform traditional shoes into IoT-shoes, for instance, already uses the data generated by these inserts to remotely diagnose certain diseases at an early stage.

The continuous progress in computer miniaturization, processing speed, and storage will pave the way to integrating IoT-components into small products even if they so far lack any electronic support [51]. In principle, IoT-products can autonomously acquire data from three sources, namely, internally from builtin sensors, externally from other IoT-products in close proximity, and from the EIS itself. Moreover, enterprises may also indirectly access data generated by third-party IoT-products that has been mutually exchanged with their own IoTproduct.

Small, everyday products can typically host only one, if any, wireless communication technology. Each technology has its advantages and drawbacks and is suitable for specific fields of application (for an overview, see Fig. 3). In the recent past the development of wireless communication technologies has focused on personal and body area networks as well as on wireless sensor networks. Bluetooth Low Energy, Wi-Fi Direct, and Near Field Communication are particularly promising technologies for small and mobile IoT-products. In general, the assessment of communication technologies for a specific IoT-product should take into account communication distance, required data throughput, latency, reliability, practicability for customers, and technology dissemination [7].

Especially for miniaturized and mobile IoT-products, energy consumption and supply constitutes a significant technical challenge. Although batteries may be an inexpensive solution, the increasing number of IoT-products will render periodic recharging and replacement of numerous batteries difficult [41, 45]. A promising approach to address this issue is energy harvesting. Energyharvesting-enabled IoT-products are capable of autonomously harnessing energy from the environment and converting it to electrical energy. Most energyharvesting methods for (miniaturized) IoT-products rely on solar $[6,38]$, wind $[14,18]$, differences in temperatures (e.g., body heat) [15, 25], movement (e.g., body movement) $[13,19,30]$, vibrations [3], radio frequency $[24,29,36]$, or microbial activity [54]. Piezo-electric materials embedded in IoT-ready shoes or light switches, for instance, generate sufficient electrical energy from controllable mechanical deformation to send radio signals over short distances to smartphones or IoT-ready light bulbs [34,42]. For a more in-depth overview of energy-harvesting techniques in wireless sensor networks, we refer to [9, 45, 47]. 


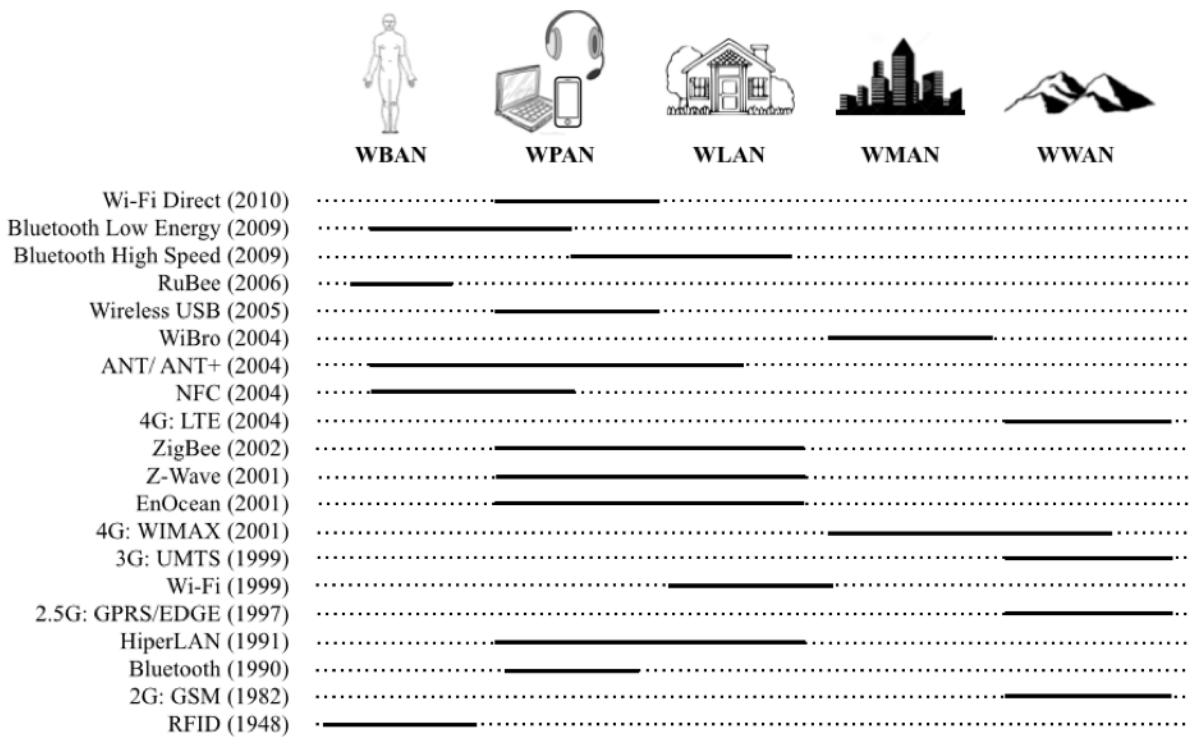

Fig. 3. Wireless communication technologies categorized by their typical field of application. $\mathrm{WBAN}=$ Wireless Body Area Network, WPAN $=$ Wireless Personal Area Network, WLAN $=$ Wireless Local Area Network, WMAN = Wireless Metropolitan Area Network, WWAN = Wireless Wide Area Network. Year of market introduction in brackets

\section{Data Collection with Product Analytics}

\subsection{Evolution of Product Analytics}

"Connected" products are a new phenomenon on the market side of enterprises. Until now, enterprises have generally lost direct access to their products at the point of sale (Mayer 2010). In order to gain deeper insights into actual product usage, product condition, and other information of interest, enterprises had to conduct resource-intense market studies and maintain extensive consumer dialogs, which leave little room for trials and feedback on a large scale [22]. For the purpose of collecting data for their EIS, enterprises more often than not resort to the internet, which has thus become a popular source for data mining, including online consumer ratings, reviews, discussions, subscriptions, and other consumer-related actions. Modern web technologies also reduce the common information asymmetry between consumers and enterprises $[4,12]$. Still, the internet has undergone development from the initial stationary internet, to the current mobile internet stage, and on to the already emerging internet of things (for an overview, see Fig. 4).

The stationary internet and web analytics have allowed capturing of consumer behavior in a novel way through company websites. Google, comScore, Adobe, and Mixpanel are currently the worldwide leading providers of well- 


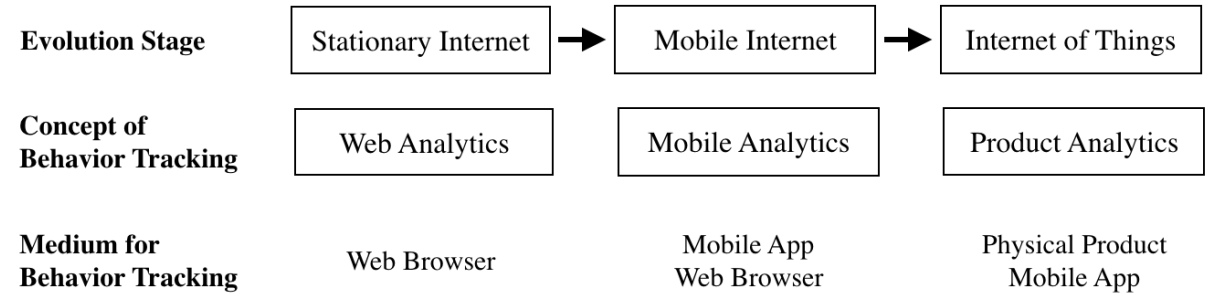

Fig. 4. The evolution of the internet of things and product analytics

established web analytics technologies. Although the web has significantly shortened the distance between enterprises and consumers, both physically and emotionally, to just a click [16], web analytics still requires consumers to generate feedback data actively on the web. The dissemination of smartphones and the mobile internet have further increased the time consumers are close to enterprises, because, in contrast to a personal computer, smartphones can be used almost anytime and anywhere (for an application example, see [48]). Thus, mobile analytics have provided new opportunities. With regard to the mobile internet, Google Analytics, Flurry Analytics, Crashlytics, and HockeyApp are popular examples of tools that capture the consumer's interaction with mobile apps and mobile web browsers. Following these predecessors, the current evolution stage of the internet, IoT, is about to establish a permanent connection between consumers and enterprises. In the future, consumers will be surrounded by IoT-products that permanently capture the consumer's interactions with IoT-products, everyday objects, and other persons. With the expansion of the internet from computers and smartphones to everyday things, the application field of tools used in web and mobile analytics likewise expands [4,12]. Thus, IoT-products constitute a promising platform to collect data about the actual product usage.

We refer to the IoT-counterpart of web and mobile analytics as "product analytics" because the medium for customer interaction is not a web browser but the physical product itself and, if available, a corresponding mobile app that functions as a remote control for the IoT-product. Although a wide range of IoT-ready products already exists on the market, the application of product analytics is still in an infant stage; standardized tools and best practices for product analytics are likely to emerge in the upcoming years. In the remainder of this section we explore established methods from web analytics and discuss their application to IoT-products.

\section{$3.2 \quad$ Log Files}

Web servers store a log of page requests including data such as the originating internet protocol (IP) address, date and time of the request, referrer, and some information about the device from which the pages are requested [16]. These log files serve as a data foundation for the most common metrics such as the frequency and duration of visits, visitor paths, demographic and geographic visitor 
information, referring websites and keywords, operating system statistics, and so forth. Data collection with log files can be executed on both the server and the client level [43]. The collected data helps enterprises to understand consumer behavior such as how consumers react to product information, how they make purchase decisions, which consumer segment is most likely to make product purchases, and reasons for consumers to bounce from (fail to follow through with) the purchase process. The insights extracted from log files are used to support decision making in various enterprise divisions and levels including communication or pricing decisions in marketing, product feature decisions in product development, training of sales representatives and technicians, etc.

IoT-products offer an attractive platform for the autonomous collection of product usage data in log files that are automatically pushed to EIS at intervals or on request. The data from built-in sensors can be analyzed in order to determine the frequency and intensity of product usage, usage patterns and triggers of product abandonment, product malfunctions, incorrect product usage, and much more. Through an EIS, these insights can be utilized to predict product maintenance and the topic of inbound calls in call centers [37], analyze the sequence of events on the customer journey [31], maintain direct relationships with consumers throughout the whole product life cycle [21], capture longitudinal data for customer relationship management $[17,39]$, or apply novel business models that consider usage behavior [11]. Amazon, for instance, uses log files to offer ebook authors per-page payouts. Another promising field of application for information being derived from log files is product optimization. Log files are an established source for capturing the behavior of website visitors in so-called $\mathrm{A} / \mathrm{B}$ tests. In these experiments, the performance of two operational versions of a website that differ in only one single variable such as a logo or a button is compared, which ultimately allows testing of hypotheses with respect to conversion rates and other visitor actions of interest. When applied to IoT-products, experimental tests of variations in digital user interfaces and product features can deliver information for EIS about consumer preferences, latent needs, cognitive capabilities of using the product, and so forth. Log file data from IoT-products can also provide insights about the consumer's environment by applying association rules to identify complementary products that consumers frequently use alongside their own IoT-products. Such association rules are currently used in the web to relate pages or objects that are frequently referenced together in a single session [43]. A common field of application is product recommendations in web shops, referring to products that "other customers also bought" using association rules to identify products that are complementary to items in the shopping cart of the consumer. In the IoT context, insights on products in the consumer's environment can also serve as a foundation to determine cross- and upselling opportunities and, moreover, they can support decision making about technical interfaces to ensure compatibility with complementary products. 
Wilhelm Klat, Christian Stummer, and Reinhold Decker

\subsection{Tagging}

Tagging is a more active method of capturing IoT-product usages. In the traditional internet, tagging describes the placement of invisible images or, more recently, pixels, in specific sections of a website or email that trigger actions when they are loaded by web browsers or email clients [16]. Unlike the rather continuous and passive data collection in log files, tagging data is pushed to the EIS in real-time if a predefined user action is tracked. When applied in IoT-products tagging is a promising method for enterprises to collect additional real-time data that can automatically trigger actions in different enterprise divisions through the EIS. As an example, IoT-product tags may indicate continued usage difficulties on the consumer's side and notify customer service to proactively contact the consumer for assistance. Real-time IoT-tagging can also be used to remotely personalize IoT-products with respect to the consumer's usage patterns, similar to website personalization [35]. Some vehicle insurance enterprises such as Metromile already offer "pay how you drive (PHYD)" policies wherein the driving behavior of consumers is taken into account in calculating premiums. A small box installed in the car of the consumer tracks the driving behavior, including driving speed, braking behavior, and turns, and sends this data to the insurance providers. Thus, tagging can instantly reveal infringements such as driving through a red traffic light, allowing the enterprise to aline premiums with actual risk.

\section{Conclusions}

The internet of things gives birth to a novel category of consumer products that can both collect data and share data. These so-called IoT-products constitute a new source of real-time consumer data for EIS. They use built-in sensors and wireless communication technologies to capture actual product usage and push data to the EIS. The current expansion of the internet from the web to physical products provides an opportunity to apply well-established methods from web analytics to IoT-products. This paper contributes to the field of research in the intersection between the IoT and EIS by highlighting new data collection opportunities for EIS. By integrating microsensors, processors, wireless communication technologies, and energy supplies into traditional products, enterprises may gain real-time access to data beyond the point of sale. In particular, everyday consumer products may serve as a platform for product analytics, as consumers use them frequently and such products are typically close to the event of interest. Tracking and analyzing actual product usage can be implemented passively with $\log$ files or actively with tagging. Both approaches provide enterprises with the means to extract insights from rich product usage data with methods such as $\mathrm{A} / \mathrm{B}$ testing and association rules.

While our work has focused on marketing and sales, future research should also analyze the opportunities of product analytics for other enterprise divisions. A second promising direction for further research in IoT and EIS lies in the development of frameworks that allow easy cross-platform application of product 
analytics in IoT-products (see, for example, $[23,46]$ ). Such platforms will ultimately be necessary for product analytics to become as successful and popular as its counterpart in the web. Finally, IoT-products pose security and privacy challenges (see, for example, $[22,44,49]$ ). In the context of product analytics, further works on data survivability, intrusion detection, and data authentication seem to be particularly worthwhile [10].

\section{References}

1. Akyildiz, I.F., Su, W., Sankarasubramaniam, Y., Cayirci, E.: Wireless sensor networks: a survey. Computer Networks 38, 393-422 (2002)

2. Bauer, S.R., Mead, P.: After you open the box: making smart products more usable, useful, and desirable through interactive technology. Design Management Journal 6, 21-26 (1995)

3. Beeby, S.P., Tudor, M.J., White N.M.: Energy harvesting vibration sources for microsystems applications. Measurement Science and Technology, 17(12), R175R195 (2006)

4. Bohn, J., Coroama, V., Langheinrich, M., Mattern, F., Rohs, M.: Living in a world of smart everyday objects: social, economic, and ethical implications. Journal of Human and Ecological Risk Assessment 10, 763-786 (2004)

5. CASAGRAS: RFID and the inclusive model for the internet of things. Final Report for EU Framework 7 Project No. 216803 (2009)

6. Chirap, A., Popa, V., Coca, E., Potorac, D.A.: A study on light energy harvesting from indoor environment: the autonomous sensor nodes. In: Proceedings of the IEEE International Conference on Development and Application Systems (DAS), pp. 127-131. IEEE Press, New York (2014)

7. Chong, C.Y., Kumar, S.P.: Sensor networks: evolution, opportunities, and challenges. Proceedings of the IEEE 91, 1247-1256 (2003)

8. Coren M.J.: Tesla has 780 million miles of driving data, and adds another million every 10 hours, http://qz.com/694520/tesla-has-780-million-miles-of -driving-data-and-adds-another-million-every-10-hours/

9. Dewan, A., Ay, S.U., Karim, M.N., Beyenal, H.: Alternative power sources for remote sensors: a review. Journal of Power Sources 245, 129-143 (2014)

10. Di Pietro, R., Guarino, S., Verde, N.V., Domingo-Ferrer, J.: Security in wireless ad-hoc networks: a survey. Computer Communications 51, 1-20 (2014)

11. Dover, C.: Worldwide SaaS enterprise applications 2014-2018 forecast and 2013 vendor shares. IDC Research, Framingham (2014)

12. Filipova-Neumann, L., Welzel, P.: Reducing asymmetric information in insurance markets: cars with black boxes. Telematics and Informatics 27, 394-403 (2005)

13. Gorlatova, M., Sarik, J., Grebla, G., Cong, M., Kymissis, I., Zussman, G.: Movers and shakers: kinetic energy harvesting for the internet of things. IEEE Journal on Selected Areas in Communications 33, 1624-1639 (2015)

14. Hsiao, C.C., Jhang, J.W., Siao, A.S.: Study on pyroelectric harvesters integrating solar radiation with wind power. Energies 8, 7465-7477 (2015)

15. Hoang, D.C., Tan, Y.K., Chng, H.B., Panda, S.K.: Thermal energy harvesting from human warmth for wireless body area network in medical healthcare system. In: Proceedings of the International Conference on Power Electronics and Drive Systems (PEDS), 1277-1282. IEEE Press, New York (2009) 
16. Jansen, B.J.: Understanding user-web interactions via web analytics. Morgan \& Claypool, London (2009)

17. Jayachandran, S., Sharma, S., Kaufman, P., Raman, P.: The role of relational information processes and technology use in customer relationship management. Journal of Marketing 69, 177-192 (2005)

18. Kamalinejad, P., Mahapatra, C., Sheng, Z., Mirabbasi, S., Leung, V.C., Liang, G.Y.: Wireless energy harvesting for the internet of things. IEEE Communications Magazine 53, 102-108 (2015)

19. Khaligh, A., Zeng, P., Zheng, C.: Kinetic energy harvesting using piezoelectric and electromagnetic technologies: state of the art. IEEE Transactions on Industrial Electronics 57, 850-860 (2010)

20. Klat, W., Decker, R., Stummer, C.: Marketing management in the era of the internet of things. Working paper, Faculty of Business Administration and Economics, Bielefeld University (2016)

21. Konana, P., Ray, G.: Physical product reengineering with embedded information technology. Communication of the ACM 50, 72-78 (2007)

22. Körling, M.: Smart products: why adding a digital side to a toothbrush could make a lot of sense. Ericsson Business Review 18, 26-31 (2012)

23. Kryvinska, N., Strauss, C.: Conceptual model of business service availability vs. interoperability on collaborative IoT-enabled eBusiness platforms. In: Bessis, N., Xhafa, F., Varvarigou, D., Hill, R., Li, M. (eds) Internet of things and intercooperative computational technologies for collective intelligence, pp. 167-187. Springer, Berlin (2013)

24. Lu, X., Wang, P., Niyato, D., Kim, D.I., Han, Z.: Wireless networks with RF energy harvesting: a contemporary survey. IEEE Communications Surveys \& Tutorials 17, 757-789 (2015)

25. Lu, X., Yang, S.H.: Thermal energy harvesting for WSNs. In: Proceedings of the IEEE International Conference on Systems Man and Cybernetics (SMC), pp. 30453052. IEEE Press, New York (2010)

26. Ma, C., Wang, J.: Enterprise information management system integration based on internet of things technology. Management \& Engineering 22, 12-15 (2016)

27. Mayer, P.: Economic aspects of smartproducts. Whitepaper, Institute of Technology Management at the University of St. Gallen (2010)

28. Meyer, G.G., Buijs, P., Szirbik, N.B., Wortmann, J.C.: Intelligent products for enhancing the utilization of tracking technology in transportation. International Journal of Operations \& Production Management 34, 422-446 (2014)

29. Mishra, D., De, S., Jana, S., Basagni, S., Chowdhury, K., Heinzelman, W.: Smart $\mathrm{RF}$ energy harvesting communications: challenges and opportunities. IEEE Communications Magazine 53, 70-78 (2015)

30. Mitcheson, P.D., Yeatman, E.M., Rao, G.K., Holmes, A.S., Green, T.C.: Energy harvesting from human and machine motion for wireless electronic devices. Proceedings of the IEEE 96, 1457-1486 (2008)

31. Norton, D.W., Pine, B.J.: Using the customer journey to road test and refine the business model. Strategy \& Leadership 41, 12-17 (2013)

32. Olson, D.L., Kesharwani, S.: Enterprise information systems: contemporary trends and issues. World Scientific, Singapore (2010)

33. Pang, Z., Zheng, L., Tian, J., Kao-Walter, S., Dubrova, E., Chen, Q.: Design of a terminal solution for integration of in-home health care devices and services towards the internet-of-things. Enterprise Information Systems 9, 86-116 (2015) 
34. Paradiso, J.A., Feldmeier, M.: A compact, wireless, self-powered pushbutton controller. In: Abowd, G.D., Brumitt, B., Shafer, S. (eds) Ubicomp 2001: ubiquitous computing. LNCS, vol. 2201, pp. 299-304. Springer, Berlin (2001)

35. Pierrakos, D., Poliouras, G., Papatheodorou, C., Spyropoulos, C.D.: Web usage mining as a tool for personalization: a survey. User Modeling and User-Adapted Interaction 13, 311-372 (2003)

36. Piñuela, M., Mitcheson, P.D., Lucyszyn, S.: Ambient RF energy harvesting in urban and semi-urban environments. IEEE Transactions on Microwave Theory and Techniques 61, 2715-2726 (2013)

37. Porter, M.E., Heppelmann, J.E.: How smart, connected products are transforming competition. Harvard Business Review 92, 64-88 (2014)

38. Raghunathan, V., Kansal, A., Hsu, J., Friedman, J., Srivastava, M.: Design considerations for solar energy harvesting wireless embedded systems. In: Fourth International Symposium on Information Processing in Sensor Networks (IPSN), pp. 457-462. IEEE Press, New York (2005)

39. Rigby, D.K., Reichheld, F.F., Schefter, P.: Avoid the four perils of CRM. Harvard Business Review 80, 101-109 (2002)

40. Romero, D., Vernadat, F.: Enterprise information systems state of the art: past, present and future trends. Computers in Industry 79, 3-13 (2016)

41. Shebli, F., Dayoub, I., M'foubat, A.O., Rivenq, A., Rouvaen, J.M.: Minimizing energy consumption within wireless sensor networks using optimal transmission range between nodes. In: Proceedings of the IEEE International Conference on Signal Processing and Communications (ICSPC), pp. 105-108. IEEE Press, New York (2007)

42. Shenck, N.S., Paradiso, J.A.: Energy scavenging with shoe-mounted piezoelectrics. IEEE Micro 21, 30-42 (2001)

43. Srivastava, J., Cooley, R., Deshpande, M., Tan, P.N.: Web usage mining: discovery and applications of usage patterns from web data. SIGKDD Explorations 1, 12-23 (2000)

44. Strazdins, G., Wang, H.: Open security and privacy challenges for the internet of things. In: Proceedings of the 10th International Conference on Information, Communications and Signal Processing (ICICS). IEEE Press, New York (2015)

45. Sudevalayam, S., Kulkarni, P.: Energy harvesting sensor nodes: survey and implications. IEEE Communications Surveys \& Tutorials 13, 443-461 (2011)

46. Tiwana, A., Konsynski, B., Bush, A.A.: Platform evolution: coevolution of platform architecture, governance, and environmental dynamics. Information Systems Research 21, 675-687 (2010)

47. Vullers, R.J.M., Schaijk, R.V., Visser, H.J., Penders, J., Hoof, C.V.: Energy harvesting for autonomous wireless sensor networks. IEEE Solid-State Circuits Magazine 2, 29-38 (2010)

48. Weber, M., Denk, M., Oberecker, K., Strauss, C., Stummer, C.: Panel surveys go mobile. International Journal of Mobile Communications 6, 88-107 (2008)

49. Weber, R.H.: Internet of things: new security and privacy challenges. Computer Law \& Security Review 26, 23-30 (2010)

50. Wei, Z.: Framework model on enterprise information system based on internet of things. International Journal of Intelligent Information Systems 3, 55-59 (2014)

51. Weiser, M.: The computer for the 21st century. Scientific American 265, 94-104 (1991)

52. Whitmore, A., Agrarwal, A., Xu, L.D.: The internet of things: a survey of topics and trends. Information Systems Frontiers 17, 261-274 (2015) 
53. Xu, L.D., He, W., Li, S.: Internet of things in industries: a survey. IEEE Transactions on Industrial Informatics 10, 2233-2243 (2014)

54. Yang, F., Wang, K.C., Huang, Y.: Energy-neutral communication protocol for very low power microbial fuel cell based wireless sensor network. IEEE Sensors Journal $15,2306-2315$ (2015) 